\title{
EFFECT OF ALPRAZOLAM AND KETAMINE ON SEIZURES INDUCED BY TWO DIFFERENT CONVULSANTS
}

\author{
Josef Herink \\ Military Medical Academy J. E. Purkyně, Hradec Králové; \\ (Rector: doc. MUDr. S. Býma, CSc.)
}

\begin{abstract}
Summary: Effect of two anticonvulsants with different mechanism of action, i.e. alprazolam and ketamine, was tested in two types of seizure activity. The first one was induced by N-(3,5-dimethoxy-4-propoxyphenylethyl)-aziridine, the second one by pentylenetetrazol. While alprazolam alleviated both the minimal as well as major paroxysms, ketamine supressed only major seizures. These effects are discussed in terms of the both N-methyl-D-aspartate and GABA receptors involvement.
\end{abstract}

Key words: Aziridines; Convulsions; Pentylenetetrazol; Rat; Experimental Therapy

\section{Introduction}

$\mathrm{N}$-(3,5-dimethoxy-4-propoxyphenylethyl)-aziridine or FAZ-4 is the most interesting representative of groups of aziridine derivatives, which were formerly synthetised at the Chemical centre of the Slovak Academy of Sciences in Bratislava according to the original US patent (13).

We estimated the toxicity of aziridine derivatives following the method of Weil (16). These compounds are mildly toxic, but FAZ-4 was the most toxic within them (7). We also studied the effects of intracerebral administration of FAZ-4 on some qualitative indicators of learning and memory, FAZ-4 induced a disturbance of spatial orientation in a $\mathrm{T}$ maze. The influencing of operant conditioning in the Skinner box had a very similar course of events $(8,9)$. Furthermore, FAZ-4 was the only aziridine derivative tested which possesses the convulsive activity. This one is comparable with pentylenetetrazol (PTZ) paroxysm (see, e.g.4,11),with one exception: the lack of tonic component of major PTZ paroxysm (5). Presuming different sites of origin for the tonic and clonic component, i.e., the forebrain in case of clonic, and the brainstem in case of tonic component $(3,14,15)$, we can therefore exclude the brainstem as the site of convulsive activity of FAZ-4. The aim of the present work is an evaluation of two anticonvulsants with different mechanisms of action, i.e. alprazolam and ketamine, with respect to FAZ-4 induced seizure activity. This contingent anticonvulsive efficacy of the both drugs tested is also compared with the same ability of them in the case of classical convulsive agent PTZ.

\section{Material and Methods}

The experiments were carried out on a total number of 144 male Wistar rats (VELAZ, Praha), weighing 200 - $260 \mathrm{~g}$.
The animals were fed with standard Larsen diet and had free access to water. The rats were randomly divided into groups of 8 animals. Occurence of abnormal signs, especially the feature and intensity of the convulsions, was evaluated according to specially elaborated scale $(10,11)$, described in details previously (5). Maximum rate in this scale (equal to 5) corresponds to the generalized tonic-clonic seizures (convulsions) represented by the loss of the righting reflex at the beginning of the tonic phase and tonicclonic seizures involving muscles of forelimbs, hindlimbs, and whole body.

FAZ-4 was administered intraperitoneally in a dose of $50 \mathrm{mg} / \mathrm{kg}$. Its effect was compared with the model convulsive drug PTZ, injected subcutaneously in a dose of $100 \mathrm{mg} / \mathrm{kg}$.

Both convulsants were freshly dissolved in saline. Alprazolam (VÚFB, Prague) and ketamine (KetalarR, ParkeDavis, Madrid) were given intraperitoneally either $30 \mathrm{minu}-$ tes prior, or 1 minute subsequently, to administration of the convulsants tested. Doses used were 0,1 and $0,5 \mathrm{mg} / \mathrm{kg}$ for alprazolam, 10 and $25 \mathrm{mg} / \mathrm{kg}$ for ketamine. Following the administration of the drugs, the animals were placed into the experimental cage and individually observed for a period of 30 minutes after the last injection. The animals were always assigned the highest convulsive score observed and the average score was calculated for all groups (always 8 animals in each) and doses. The lethality of the animals within 48 hours after all experiments was recorded. The results were statistically evaluated by means of t-test. The level of significance was set at the $5 \%$ level.

\section{Results}

A lack of any tonic component of major paroxysm following DSP-4 was confirmed with respect to PTZ (compa- 
re upper and bottom left columns in Figures). Doses of both convulsants tested represent more than LD50 value.

Alprazolam exerted a biphasic effect on the PTZ convulsions. The lower dose used increased intensity of these symptoms, while for the higher dose a strong anticonvulsive effect, especially in case of subsequent administration, was observed (Fig. 1, above). On the contrary, alprazolam always showed anticonvulsive effect against FAZ-4 induced seizures, with exception of prior administration of the lower dose used (Fig. 1, below). In addition to it, alprazolam had a strong positive effect on survival of animals following administration of all doses of convulsants tested.
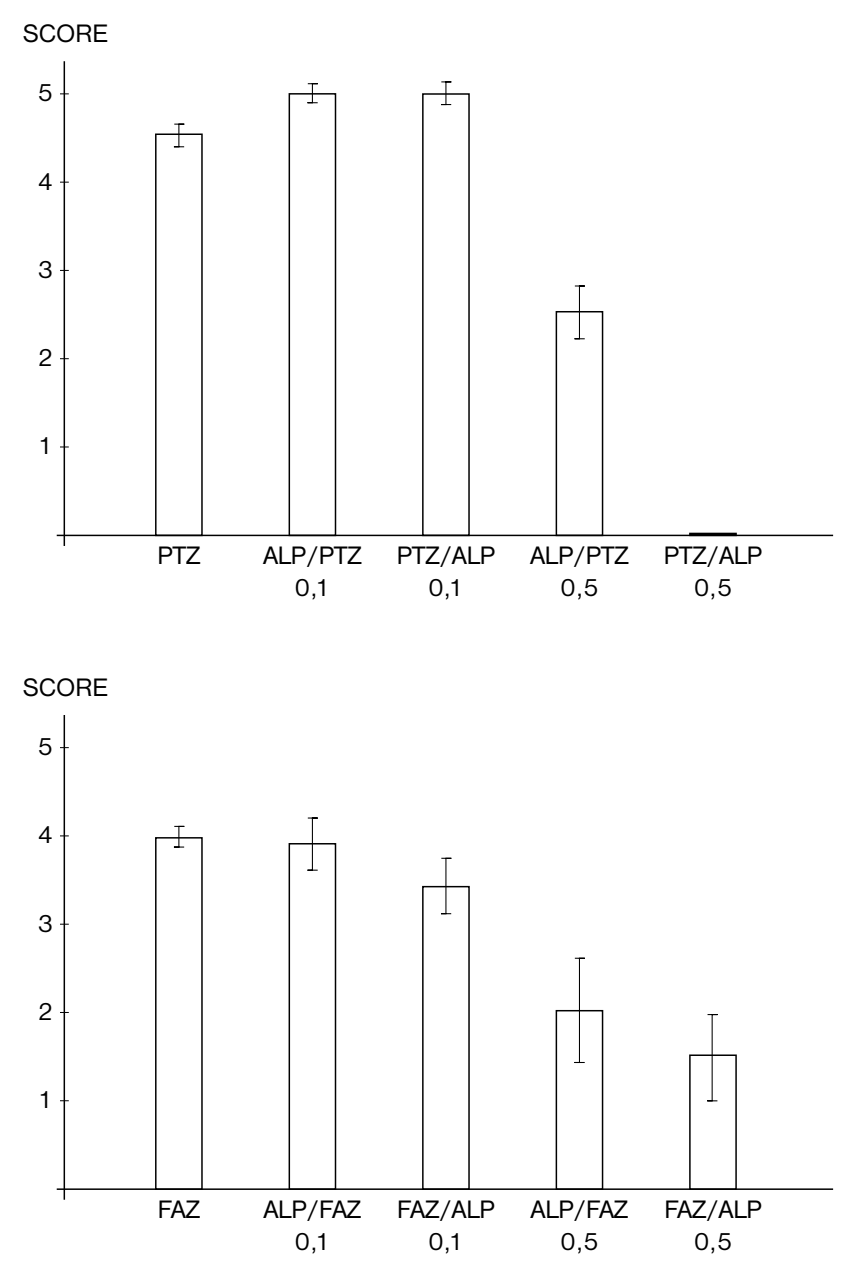

Fig. 1: The influence of alprazolam (ALP) on PTZ-induced (top) and FAZ-4-induced (bottom) seizure activity. The results are represented as means with SD of a total score of seizure activity. The numbers $(0.1,0.5)$ indicate used doses of ALP. The letters represent the order of drugs tested administration (i.e. prior or subsequent administration of ALP with respect to the convulsants tested). The numbers in the base of each column indicate the lethality (number of died animals to the total number of animals in each group).
Ketamine suppressed the PTZ convulsions at the higher dose tested (Fig. 2, above), subsequent administration of this drug (i.e., 1 minute after PTZ) was more effective than that of prior injection (i.e., 30 minutes before PTZ). Ketamine was more effective in the suppression of the FAZ-4 induced convulsion in case of subsequent administration of both doses tested (Fig. 2, below). Ketamine decreased significantly the lethality in animals. This protection was more evident in PTZ than in DSP-4 intoxication.
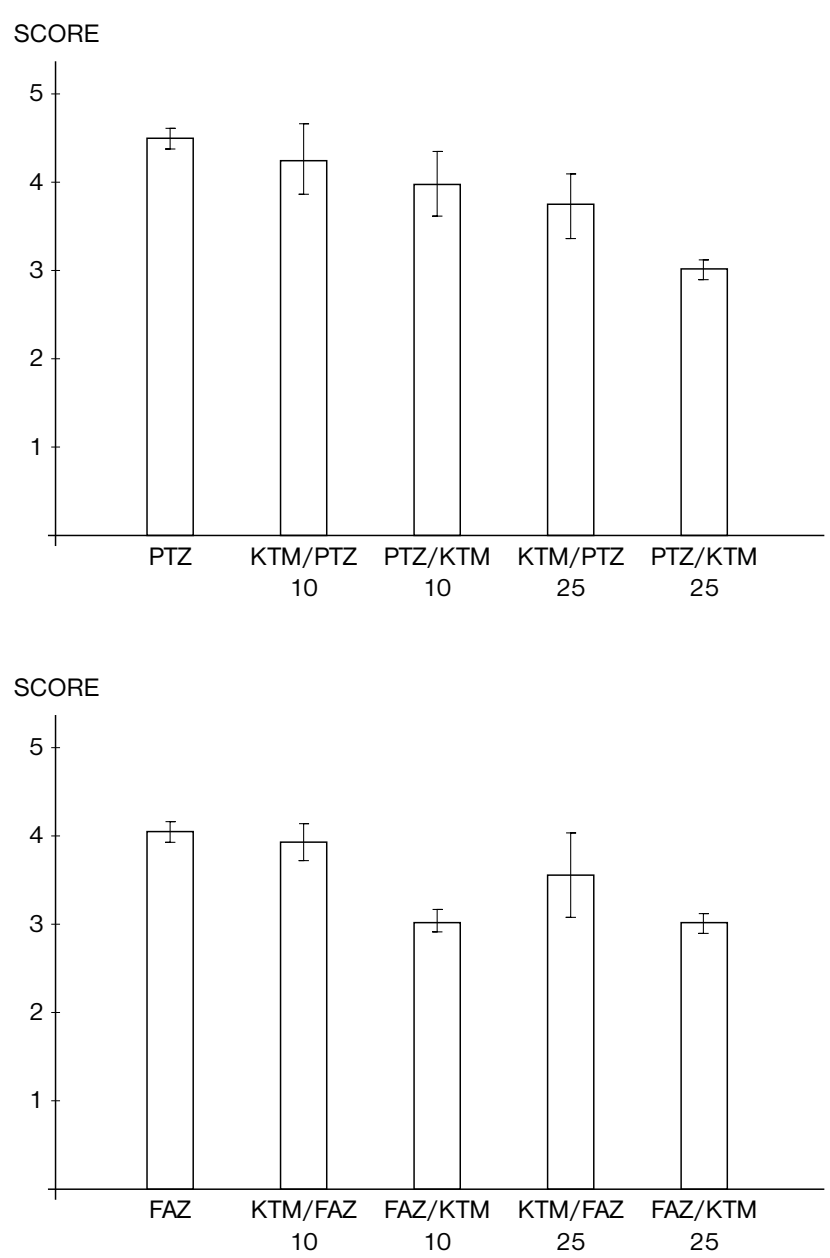

Fig. 2: The influence of ketamine (KTM) on PTZ-induced (top) and FAZ-induced (bottom) seizure activity. Other details as in Fig. 1.

\section{Discussion}

Convulsive effects and their influence is connected directly or indirectly with number of neuromediators, similarity as it was demonstrated for cholinergic and peptidergic systems $(1,4)$ or organophosphates $(2)$. PTZ is the prototype agent in the class of systemic convulsants. Nevertheless its 
mechanism of action is only poorly understood. At a synaptic level PTZ appears to interact with the GABA receptorbenzodiazepine complex $(4,12)$. However other mechanisms for PTZ-induced seizures must also be important, we suppose that it would be NMDA-receptors involvement with respect especially to the major paroxysms.

Anticonvulsant tested suppressed seizures in different manner. Alprazolam was effective against minimal as well as major seizures, while ketamine suppressed only major seizures. Regarding to presumed N-methyl-D-aspartate (NMDA) antagonistic properties of ketamine, there is a little possibility of the involvement of these receptor system in the origin and propagation of minimal seizure phenomenon $(14,15)$. Strong anticonvulsive activity of benzodiazepines, especially alprazolam, suggests the GABA receptorchloride ionophore complex involvement in the origin and propagation not only in case of PTZ- but FAZ-4 convulsions too (6,7). Discrepancy between „proconvulsive“ effect of lower dose tested of alprazolam on the one hand, and decreased lethality of animals in the same situation on the second hand, excludes largely straightforward chain of events leading from major paroxysm to the death itself.

\section{Acknowledgement:}

Author wish to thank Mrs. J. Bajgarová for skilfull technical assistance.

This work was supported by grant No. 307/95/1537 from the Grant Agency of the Czech Republic.

\section{References}

1. Bajgar J. Biological monitoring of exposure to nerve agents. Br J Ind Med 1992;19:648-53.

2. Bajgar J, Herink J, Skopec F, Hrdina V, Patočka J, Vičar

J. Modulation of cholinergic nerve transmission by leucin5enkephalin. Sb Ved Pr Lek Fak Univeryity Karlovy Hradec Králové 1985;28:47-54.

3. Browning RA. Role of the brain-stem reticular formation in the tonic-clonic seizures: Lesions and pharmacological studies. Fed Proc 1985;44:2425-31.

4. Fisher RS. Animal models of the epilepsies. Brain Res Rev 1989; 14:245-78.

5. Herink J. Convulsive properties of N-(3, 5-dimethoxy-4propoxyphenylethyl)-aziridine and their influencing by diazepam and triazolam. Sb Ved Pr Lek Fak Univerzity Karlovy Hradec Králové 1995;38:85-8.
6. Herink J, Koupilová M, Bajgar J. Effect of triazolam in convulsions induced by pentylenetetrazol. Homeostasis 1991;33:181.

7. Herink J, Koupilová M, Krs O, Bajgar J, Patočka J. Modelling of some neuropathological states of the central nervous system by aziridine derivatives. Cesk Fyziol, 1992;41(suppl.):7-10.

8. Koupilová M, Herink J. Attend to antagonize DSP-4 induced impairment of the performance of rats in a T-maze. Homeostasis 1994;36:41-3.

9. Koupilová M, Herink J, Bajgar J. Effects of aziridine derivative $\mathrm{N}$-(3,5-dimethoxy-4-propoxyphenylethyl)-aziridine on learning and memory in laboratory rats. Homeostasis 1993;34:117-20.

10. Mareš P, Marešová D, Schickerová R. Effect of antiepileptic drugs on metrazol convulsions during ontogenesis in the rat. Physiol Bohemoslov 1981;30:113-21.

11. Mareš P, Mirvaldová H, Bělská M. Influence of a new antiepileptic drug ORG637O on metrazol-induced seizures in rats during ontogenesis. Physiol Bohemoslov 1990;39: 199-205.

12. Olsen RW. The GABA postsynaptic membrane receptor-ionophore complex. Site of action of convulsant and anticonvulsant drugs. Moll Cell Biochem 1981;39:261-79.

13. Razdan K. US patent office 3.637.622, 1972.

14. Velíšek L, Kusá R, Kulovaná M, Mareš P. Excitatory amino acid antagonists and pentylenetetrazol-induced seizures during ontogenesis. I. The effects of 2-amino-7-phosphoheptanoate. Life Sci 1990;46:1349-57.

15. Velíšek L, Kulhánková I, Roztočilová L, Mareš P. Ethosuximide affects both pentylenetetrazole-and kainateinduced clonic seizures. Can J Physiol Pharmacol 1989;67:1357-61.

16. Weil CS. Tables for convenient calculation of median-effective dose (LD50 or ED50) and instruction in their use. Biometrics 1952;8:249-63.

Submitted May 1997.

Accepted June 1997.

MUDr. Josef Herink, DrSc., Purkyně Military Academy, P.O.Box 35,

50001 Hradec Králové, Czech Republic. 